\title{
Beyond Safe Operating Space: Finding Chemical Footprinting Feasible
}

Posthuma, Leo; Bjørn, Anders; Zijp, Michiel C.; Birkved, Morten; Diamond, Miriam L.; Hauschild, Michael Zwicky; Huijbregts, Mark A. J.; Mulder, Christian; Van de Meent, Dik

\section{Published in:}

Environmental Science and Technology

Link to article, DOI:

$10.1021 / \mathrm{es} 501961 \mathrm{k}$

Publication date:

2014

Link back to DTU Orbit

Citation (APA):

Posthuma, L., Bjørn, A., Zijp, M. C., Birkved, M., Diamond, M. L., Hauschild, M. Z., Huijbregts, M. A. J., Mulder, C., \& Van de Meent, D. (2014). Beyond Safe Operating Space: Finding Chemical Footprinting Feasible. Environmental Science and Technology, 48(11), 6057-6059. https://doi.org/10.1021/es501961k

\section{General rights}

Copyright and moral rights for the publications made accessible in the public portal are retained by the authors and/or other copyright owners and it is a condition of accessing publications that users recognise and abide by the legal requirements associated with these rights.

- Users may download and print one copy of any publication from the public portal for the purpose of private study or research.

- You may not further distribute the material or use it for any profit-making activity or commercial gain

- You may freely distribute the URL identifying the publication in the public portal 


\section{FINDING CHEMICAL FOOTPRINTING FEASIBLE}

4 Leo Posthuma ${ }^{1, *}$, Anders Bjørn ${ }^{2}$, Michiel C. Zijp ${ }^{1,4}$, Morten Birkved ${ }^{2}$, Miriam L. Diamond ${ }^{3}$,

5 Michael Z. Hauschild ${ }^{2}$, Mark A.J. Huijbregts ${ }^{4}$, Christian Mulder ${ }^{1}$, Dik Van de Meent ${ }^{1,4}$

6

$7 \quad$ * Corresponding author: Leo Posthuma, RIVM, E: leo.posthuma@rivm.nl

$8{ }^{1}$ RIVM, Centre for Sustainability, Environment and Health, P.O. Box 1, 3720BA Bilthoven,

9 The Netherlands

10

${ }^{2}$ DTU Management Engineering, Quantitative Sustainability Assessment, Technical University of Denmark, 2800 Kgs. Lyngby, Denmark

${ }^{3}$ Dept Earth Sciences, 22 Russell Street, University of Toronto, Toronto, M5S 3B1, Canada

${ }^{4}$ Dept Environmental Science, Institute for Water and Wetland Research, Radboud 


\section{Overshoot?}

Environmental overshoot occurs when human demands exceed the biosphere's regenerative capacities (1). Earth Overshoot Day (EOD) marks the day that humanity's footprint exhausts the Earth's annual regenerative capacity. The EOD of 2013, on August $20^{\text {th }}$, was memorable for the first author as it fell on his mother's $89^{\text {th }}$ birthday. Each EOD, falling earlier every year, confronts us with urgent environmental problems, some of which poorly defined. One such example is chemical pollution, which threatens the Earth's capacities. Rockström et al. (2) listed chemical pollution as an important but yet undefined boundary in their selection of planetary boundaries delineating the 'safe operating space for humanity'. Can we use the well-known concept of 'ecological footprints' to express a chemical pollution boundary aimed at preventing the overshoot of the Earth's capacity to assimilate environmental pollution? Current literature blossoms with ideas on this, and shows the benefits of trans-disciplinary collaborations. Borrowing our subtitle from Don Mackay's seminal paper that introduced fugacity-based modeling for quantifying the environmental distribution of chemicals (3), we now see the development of chemical footprinting that is feasible, relevant, and necessary for expressing the overshoot of the Earth's capacity. With widespread 'chemical overshoot' leading to adverse effects of pollution, we argue for implementing a solution-focused assessment paradigm: Chemical footprinting helps identify scenarios that allow us to avoid 'chemical overshoot' beyond the Earth's safe operating space.

\section{Chemical footprints}

The signs of chemical overshoot have been obvious for decades. Published in 1962, Rachel Carson's Silent Spring described with deadly accuracy the transgressions of chemical thresholds. 
Carson showed that pesticide emissions were insufficiently diluted to be safe. Three decades later, the ecological footprint concept was introduced (4), arguing that cities appropriate goods and services from a land footprint far exceeding that of their municipal boundaries. The ecological footprint allowed for conceptualizing, and later quantifying, the extent to which cities and citizens overshoot their resource boundaries. Borrowing from the concept of ecological footprints and expanding on Mackay's principles, several research teams currently propose new methods for estimating chemical footprints to situate anthropogenic pollution vis-à-vis the Earth's safe boundaries. They argue for defining the chemical footprint as a dilution requirement necessary to maintain safe concentrations, rejuvenating the adage that 'the solution to pollution is dilution'. Chemical footprinting uses chemical emissions and fugacity-based modeling, together with ecotoxicological data and mixture modeling to predict chemical impacts in relation to boundaries established to prevent ecological damage. Chemical footprints are expressed as ratios of required to available water volumes within defined geographic areas: ratios below and above unity reflect safe versus unsafe dilution space for emitted chemicals. Empirical evaluation of the chemical footprints using case studies show that the footprints capture observed trends. We propose that chemical footprinting can be used to assess the 'safe operating space' needed to dilute chemical pollution.

\section{Ecological thresholds and boundaries of chemical pollution?}

The literature on the safe operating space with respect to chemical pollution discusses safe boundaries (B) and natural thresholds (T) beyond which ecosystems collapse (Figure 1). Stressor interactions and other numerous unknowns imply that $\mathrm{B}$ must lower than $\mathrm{T}$ to remain safe, but both are difficult to define. Mulder et al. (5) recently quantified concrete thresholds and real 
vulnerabilities for 18 near-pristine rivers using food-web modeling, from which we derive several insights (Figure 1). One: different locations harbor different food webs. Two: food-web resilience to chemicals differs, implying web-specific and trait-mediated T's. Three: when T's are exceeded, distinct collapse trajectories imply different vulnerabilities (V). Four: effects caused if a stressor acts randomly across the food web are different from those occurring when only a single trophic level is affected. For example, herbicides cause different responses than neurotoxic or narcotic compounds, as reflected in the shifted T's and V's. Ecological analyses help to locate natural thresholds and allow for establishing safe pollution boundaries.

\section{Challenges remain!}

Ecological analyses solve some, but not all challenges. Many unanswered questions remain. How can we use ecological studies to derive predictive thresholds related to collapse? How can we locate ecological thresholds of chemical pollution that account for multiple stressors? What distance should separate B and T to remain safe and is this distance ecosystem specific? Next, ecology teaches that some species have key ecosystem functions, making us aware of cascading effects. Does this imply that we should derive chemical footprints for key species like pollinators? And because we are dealing with a global phenomenon, how do we aggregate local information into a global safe operating space, acknowledging that both chemical exposures and environmental thresholds vary geographically? Other challenges lie ahead as well. While methods of chemical footprinting have been proposed, data are always needed to make them operational. However, data on emissions, environmental characteristics and fate processes, and chemical-specific, as well as mixture ecotoxicity are often insufficient, particularly in poorly studied regions. Environmental science has reached a level of maturity that enables expression 
and quantification of chemical footprints. However, relating footprints to planetary boundaries needs data or, more importantly, ways to surmount data gaps and needs interdisciplinary bridging between chemical and ecological concepts.

\section{Proceed while developing}

Silent Spring has not yet led to an impact-free 'Summer'. To help us reach such a 'Summer', we suggest footprinting be used to convey the urgency of, and act on environmental overshoot. The footprint as an indicator is readily understood and used, as seen by its expansion from land to carbon and water. Building on this concept, the chemical footprint employs well-developed environmental science and related tools, to express the proximity of an ecosystem to established boundaries. A chemical footprint summarizes complex information that can be used by citizens, educators and regulators to foster the sustainable use of chemicals and thereby steer us away from overshooting the Planetary Boundary for chemical pollution.

\section{References}

(1) Wackernagel, M.; Schulz, N. B.; Deumling, D.; Linares, A. C.; Jenkins, M.; et al., Tracking the ecological overshoot of the human economy. Proceedings of the National Academy of Sciences 2002, 99, 9266-9271.

(2) Rockström, J.; Steffen, W.; Noone, K.; Persson, Å.; Chapin III, F. S.; et al., A safe operating space for humanity. Nature 2009, 461, 472-475.

(3) Mackay, D., Finding fugacity feasible. Environmental Science and Technology 1979, 13, 12181223.

(4) Rees, W. E., Ecological footprints and appropriated carrying capacity: what urban economics leaves out. Environment \& Urbanization 1992, 4, 121-130. 
(5) Mulder, C.; Boit, A.; Mori, S.; Vonk, J. A.; Dyer, S. D.; et al., Distributional (in)congruence of biodiversity-ecosystem functioning. Advances in Ecological Research 2012, 46, 1-88.

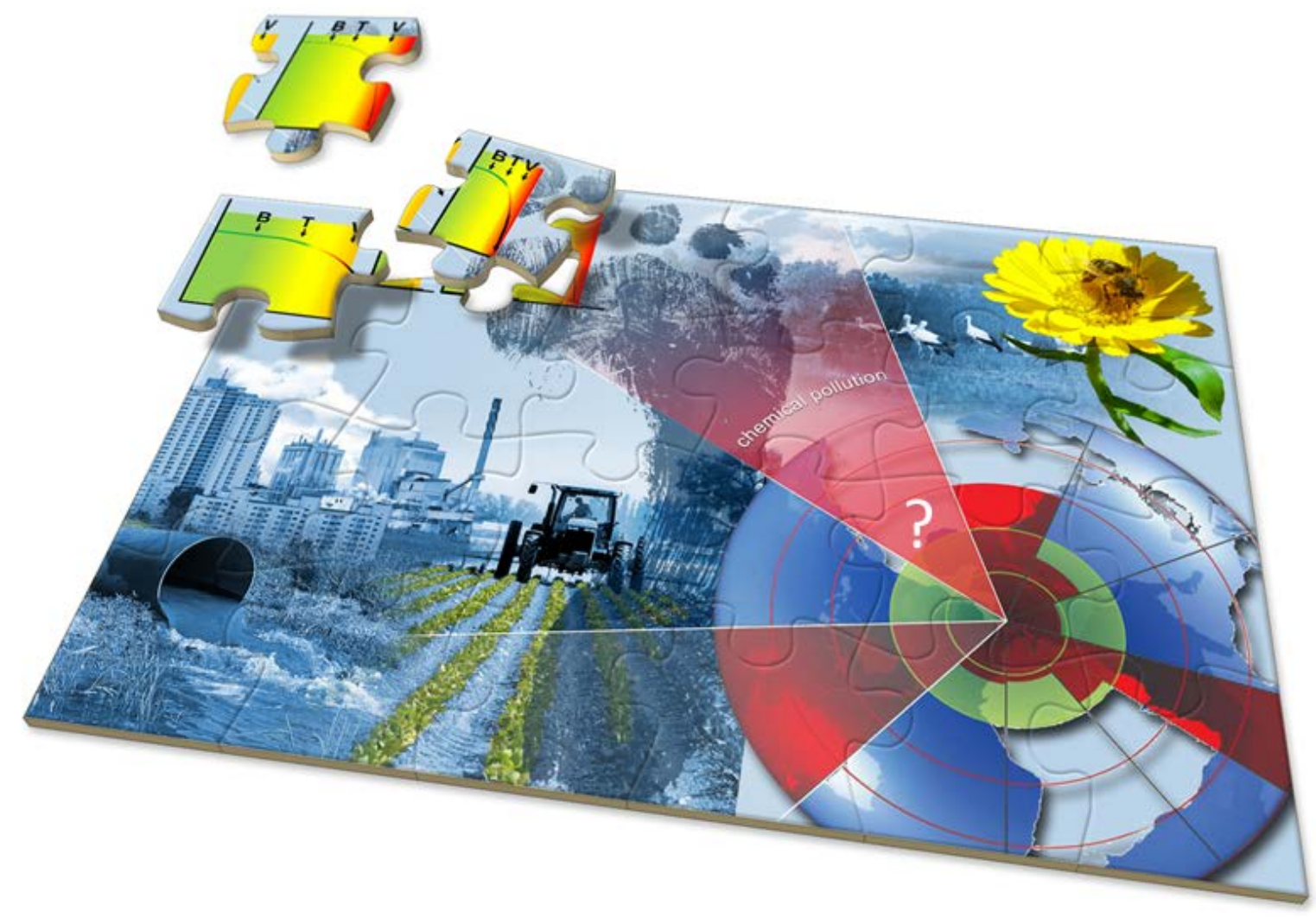

Figure 1. Emissions result in footprints for different systems. Ecological studies (upper left) are needed to derive thresholds (T) and vulnerabilities (V) from disintegration trajectories. Boundaries (B) are defined to stay within the 'safe operating space'. Background inspired by (2) and adapted by permission from Macmillan Publishers Ltd: Nature.

<TO BE PLACED WITHIN THE 'Ecological thresholds and boundaries of chemical pollution?' SECTION> 